\title{
Clinical significance and determinants of the universal definition of perioperative bleeding classification in patients undergoing coronary artery bypass surgery
}

\author{
Eeva-Maija Kinnunen, MS, ${ }^{a}$ Tatu Juvonen, MD, PhD, ${ }^{a}$ Kari Eino Juhani Airaksinen, MD, PhD, ${ }^{b}$ \\ Jouni Heikkinen, $\mathrm{MD}, \mathrm{PhD},{ }^{\mathrm{a}}$ Ulla Kettunen, $\mathrm{RN},{ }^{\mathrm{a}}$ Giovanni Mariscalco, $\mathrm{MD}, \mathrm{PhD},{ }^{\mathrm{c}}$ and \\ Fausto Biancari, $\mathrm{MD}, \mathrm{PhD}^{\mathrm{a}}$
}

Objectives: We evaluated the clinical significance and identified the predictors of the universal definition of perioperative bleeding (UDPB) classes in patients undergoing isolated coronary artery bypass grafting (CABG).

Methods: Data on antithrombotic medication, perioperative bleeding, blood transfusion, and adverse events were available for 2764 patients who had undergone isolated CABG.

Results: The Papworth risk score correlated significantly with the UDPB classes (rate of UDPB class 3-4 and Papworth risk score of $0,12.1 \% ; 1,23.9 \% ; 2,37.5 \%$; and $3,45.0 \% ; P<.0001)$. Ordinal regression showed that increased age, female sex, low body mass index, low estimated glomerular filtration rate, low hemoglobin, dialysis, urgent or emergency operation, critical status, on-pump surgery, potent antiplatelet drug pause of $<5$ days, and warfarin pause of $<2$ days were independent predictors of high UDPB classes. These risk factors also predicted UDPB classes 3-4 in logistic regression analysis. Increasing UDPB classes were associated with an increased risk of in-hospital mortality $(P=.002)$, stroke $(P=.023)$, low cardiac output $(P<.0001)$, prolonged use of inotropes $(P<.0001)$, renal replacement therapy $(P<.0001)$, length of stay in the intensive care unit $(P<.0001)$, and late mortality $(P<.0001)$ as assessed by multilevel propensity score-adjusted analysis. Similar findings were observed in the propensity score-adjusted analysis for the most severe grades of perioperative bleeding (ie, UDPB class 3-4).

Conclusions: High UDPB classes were associated with significantly poorer immediate and late outcomes. The UDPB classification seems to be a valuable research tool to estimate the severity of bleeding and its prognostic impact affect after coronary surgery. (J Thorac Cardiovasc Surg 2014;148:1640-6)

Supplemental material is available online.

Significant perioperative bleeding ${ }^{1,2}$ and the related need of blood transfusion ${ }^{2,3}$ are known to make patients susceptible to adverse outcomes. However, the magnitude at which bleeding and the transfusion of blood products become clinically significant is unknown. Dyke and colleagues ${ }^{1}$ recently proposed a classification for the severity of

From the Division of Cardiothoracic and Vascular Surgery, ${ }^{a}$ Department of Surgery, Oulu University Hospital, Oulu, Finland; Heart Center, ${ }^{b}$ Turku University Hospital and University of Turku, Turku, Finland; and Department of Heart and Vessels, Cardiac Surgery, ${ }^{\mathrm{c}}$ Varese University Hospital, Varese, Italy.

Disclosures: Fausto Biancari reports lecture fees from AstraZeneca. K. E. Juhani Airaksinen reports consulting fees from Bayer and Boehringer Ingelheim. All other authors have nothing to disclose with regard to commercial support.

Received for publication April 21, 2014; revisions received June 8, 2014; accepted for publication July 7, 2014.

Address for reprints: Fausto Biancari, MD, PhD, Division of Cardiothoracic and Vascular Surgery, Department of Surgery, Oulu University Hospital, PO Box 21, Oulu 90029, Finland (E-mail: faustobiancari@yahoo.it).

0022-5223/\$36.00

Copyright (C) 2014 by The American Association for Thoracic Surgery

http://dx.doi.org/10.1016/j.jtcvs.2014.07.040 perioperative bleeding in patients undergoing adult cardiac surgery, the universal definition of perioperative bleeding (UDPB) (Table E1). This classification is based on a logical, but still arbitrary, weighting of the amount of postoperative blood loss, the need for blood products, and the need for pharmacologic measures to treat significant perioperative bleeding. The clinical significance of this classification has been evaluated to date only by its proposers. The aim of the present study was to validate the UDPB classification and identify the risk factors predicting high UDPB classes in patients undergoing isolated coronary artery bypass grafting $(\mathrm{CABG})$.

\section{METHODS}

\section{Patient Population and Data Collection}

The present study included 2764 consecutive patients who had undergone isolated CABG from June 2006 to December 2013 at the Oulu University Hospital (Oulu, Finland). The study included elective, urgent, and emergency operations performed in either an off-pump or on-pump setting.

Complete pre-, intra-, and postoperative data were available for all patients from an institutional electronic cardiac surgery database containing the baseline and operative data and data on immediate postoperative adverse events. Data on the preoperative use of warfarin, clopidogrel, prasugrel, and ticagrelor and the perioperative use of 


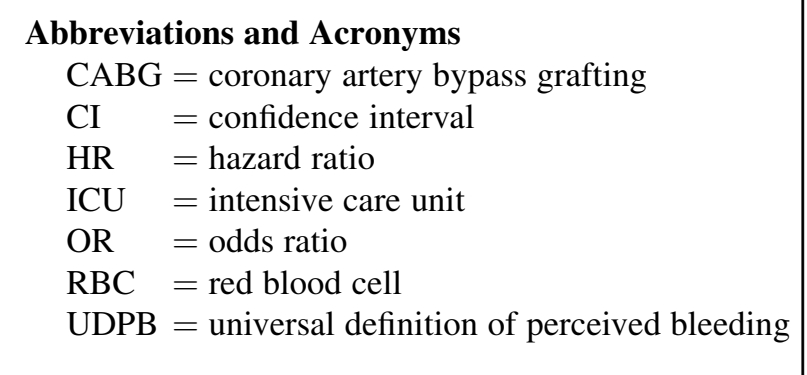

prothrombin complex concentrate and recombinant factor VIIa were collected retrospectively. The amount of transfused blood products, such as red blood cells (RBCs), platelets, and solvent/detergent-treated plasma (Octaplas; Octapharma AG, Lachen, Switzerland), was retrieved from a prospective electronic hospital registry that collected data on any transfusion of blood products. Data on the amount of postoperative blood loss were retrieved from a prospective electronic registry of our intensive care unit (ICU). The patient characteristics are summarized in Tables E2 and E3.

The glomerular filtration rate was estimated using the Modification of Diet in Renal Disease formula. ${ }^{4}$ The clinical variables were defined according to the EuroSCORE II definition criteria. ${ }^{5}$ The bleeding risk was estimated according to the Papworth bleeding risk score. ${ }^{6}$ The UDPB classification ${ }^{1}$ was used to stratify the severity of perioperative bleeding (Table E1). Data on patient death were retrieved from the Central Statistical Office of Finland (Tilastokeskus), which collects the certificates of death for all inhabitants of Finland. The data for the present study were provided up to December 31, 2013. We have assumed that no data on immediate and late death were missing for the present study population.

\section{Perioperative Antithrombotic Treatment, Blood Transfusion, and Resternotomy for Excessive Bleeding}

The main strategy for patients referred for elective surgery was that warfarin was discontinued 2 days before surgery and no heparins were given preoperatively. Enoxaparin was used preoperatively, instead of warfarin, only in selected patients with acute coronary syndromes or a mechanical heart valve. Potent antiplatelet drugs (clopidogrel, prasugrel, and ticagrelor) were discontinued for $\geq 5$ days when feasible (ie, when the patient's condition allowed us to postpone surgery for a few days). Aspirin was discontinued for 7 days during the first part of the study period until 2012; subsequently, it was continued until surgery.

Heparin $(3.0 \mathrm{mg} / \mathrm{kg})$ was administered intravenously after sternotomy to maintain an activated coagulation time of $>450$ seconds, and it was neutralized at the end of the procedure by protamine sulfate $(3.0 \mathrm{mg} / \mathrm{kg})$. Additional protamine was given in the case of bleeding during closure of the chest or within the first hour after surgery according to the activated coagulation time. Aprotinin was not used in any of these patients. Tranexamic acid was administered intraoperatively at the discretion of the anesthesiologist. Packed leukoreduced RBCs were transfused on the day of operation if the hemoglobin was $<90 \mathrm{~g} / \mathrm{L}$. Later, leukoreduced RBCs were transfused if the hemoglobin was $<80 \mathrm{~g} / \mathrm{L}$. Octaplas and platelets were transfused according to the amount of intra- and postoperative bleeding, international normalized ratios, and the platelet count. Recombinant factor VII was used only in cases of unrelenting massive bleeding. Resternotomy was performed in the case of excessive bleeding according to criteria previously described.

All blood lost during the operation was collected into a cell saver reservoir and washed. Salvaged RBCs were transfused during or at completion of the operation. Mediastinal blood/fluid was collected after surgery in a sterile collection chamber connected to $15-\mathrm{cm} \mathrm{H}_{2} \mathrm{O}$ wall suction by an underwater seal and then discarded.

Enoxaparin (40-80 mg once daily) was started the evening of surgery for those patients without excessive bleeding $(<1000 \mathrm{~mL})$. Aspirin $100 \mathrm{mg}$ was restarted on the first postoperative day. Warfarin was started on the first postoperative day in patients receiving chronic oral anticoagulation unless significant bleeding had occurred or started de novo in the case of persistent atrial fibrillation. Clopidogrel and ticagrelor were used postoperatively only in the case of allergy to aspirin or recent percutaneous coronary intervention.

Platelet function was not tested preoperatively in these patients. The activated coagulation time was measured before heparin administration, intraoperatively, and 20 to 30 minutes after protamine administration. The activated coagulation time was measured later in the case of excessive bleeding. Additional doses of protamine were given in the case of significant bleeding and a prolonged activated coagulation time compared with the preoperative level. Thromboelastography was performed postoperatively in the case of excessive bleeding during the last 2 years of the study period.

\section{Operative Techniques}

Intermittent antegrade and retrograde cold blood cardioplegia was used during on-pump CABG. Epiaortic ultrasonography was performed according to surgeon preference. The ascending aorta was left untouched in the case of a grade III diseased aorta. ${ }^{8}$ Proximal anastomoses were sutured to the ascending aorta during side clamping or crossclamping, when considered safe. The Octopus stabilizer (Medtronic, Minneapolis, $\mathrm{MN}$ ) and intracoronary shunts were routinely used in patients who underwent off-pump CABG.

\section{Outcome Endpoints}

The UDPB classes were the outcome endpoints of interest in the analysis to identify the predictors of severe bleeding. UDPB was then dichotomized (UDPB class $0-2$ vs $3-4$ ), because the preliminary analysis showed that UDPB classes 3 and 4 were associated with markedly poorer outcomes.

The other outcome endpoints of interest were in-hospital and late mortality, length of stay in the ICU, low cardiac output syndrome (postoperative cardiac index $<2.0 \mathrm{~L} / \mathrm{min} / \mathrm{m}^{2}$, measured at least twice), a prolonged use of inotropes ( $>12$ hours), intra-aortic balloon pump, stroke, renal replacement therapy, atrial fibrillation, postoperative blood loss after 12 hours, resternotomy for excessive bleeding, number of RBC units, Octaplas units, and platelet units transfused, and the use of prothrombin complex concentrate and recombinant factor VIIa.

Stroke was defined as a new, neurologic deficit after surgery lasting $>24$ hours and accompanied by new structural changes on computed tomography or magnetic resonance imaging. Renal replacement therapy was defined as postoperative renal failure requiring temporary or prolonged dialysis. The RBC, Octaplas, and platelet units and prothrombin complex concentrate and recombinant factor VIIa were counted from the operation day to a maximum of 1 month postoperatively. Cryoprecipitate was not used in the study population.

\section{Ethical Considerations}

The institutional review board of the Oulu University Hospital approved the study protocol.

\section{Statistical Analysis}

Statistical analysis was performed using SPSS, version 22.0, statistical software (IBM Corp, Armonk, NY). No attempt to replace missing values was made. The Fisher exact test, chi-square test, Mann-Whitney $U$ test, and Kruskal-Wallis test were used for univariable analysis. Correlations between continuous and ordinal variables were estimated using the 
TABLE 1. Outcomes for overall study population stratified by universal definition of perioperative bleeding class

\begin{tabular}{|c|c|c|c|c|c|c|c|}
\hline \multirow[b]{2}{*}{ Outcome endpoints } & \multirow[b]{2}{*}{ Overall $(n=2764)$} & \multicolumn{5}{|c|}{ UDPB class } & \multirow[b]{2}{*}{$P$ valu } \\
\hline & & $0(n=756)$ & $1(n=286)$ & $2(n=1042)$ & $3(\mathbf{n}=\mathbf{5 8 5})$ & $4(n=95)$ & \\
\hline In-hospital mortality & $66(2.4)$ & $0(0)$ & $0(0)$ & $16(1.5)$ & $30(5.1)$ & $20(21.1)$ & $<.0001$ \\
\hline ICU stay $(d)$ & $2.2(2.1-2.24)$ & $1.3(1.2-1.3)$ & $1.5(1.4-1.7)$ & $2.0(1.9-2.1)$ & $3.1(2.9-3.3)$ & $7.4(5.9-9.0)$ & $<.0001$ \\
\hline Low cardiac output syndrome & $383(13.9)$ & $50(6.6)$ & $35(12.2)$ & $135(13.0)$ & $131(22.4)$ & $32(33.7)$ & $<.0001$ \\
\hline Prolonged inotrope use ( $>12 \mathrm{~h}$ ) & $774(28.0)$ & $82(10.8)$ & $54(18.9)$ & $306(29.4)$ & $274(46.8)$ & $58(61.1)$ & $<.0001$ \\
\hline IABP & $24(0.9)$ & $1(0.1)$ & $0(0)$ & $8(0.8)$ & $9(1.5)$ & $6(6.3)$ & $<.0001$ \\
\hline Stroke & $52(1.9)$ & $5(0.7)$ & $0(0)$ & $18(1.7)$ & $24(4.1)$ & $5(5.3)$ & $<.0001$ \\
\hline RRT & $57(2.1)$ & $1(0.1)$ & $0(0)$ & $4(0.4)$ & $25(4.3)$ & $27(28.4)$ & $<.0001$ \\
\hline $\mathrm{AF}$ & $1186(42.9)$ & $250(33.1)$ & $127(44.4)$ & $454(43.6)$ & $298(50.9)$ & $57(60.0)$ & $<.0001$ \\
\hline Postoperative bleeding after $12 \mathrm{~h}(\mathrm{~mL})$ & $503(489-518)$ & $343(333-353)$ & $474(450-498)$ & $446(431-460)$ & $707(670-745)$ & $1347(1099-1594)$ & $<.0001$ \\
\hline Resternotomy for bleeding & $163(5.9)$ & $0(0)$ & $0(0)$ & $0(0)$ & $119(20.3)$ & $44(46.3)$ & $<.0001$ \\
\hline \multicolumn{8}{|l|}{ Blood products } \\
\hline $\mathrm{RBC}(\mathrm{U})$ & $2.5(2.4-2.6)$ & - & $0.7(0.7-0.8)$ & $2.3(2.2-2.4)$ & $5.3(5.1-5.5)$ & $13.3(11.8-14.8)$ & $<.0001$ \\
\hline Octaplas (U) & $1.2(1.1-1.2)$ & $0.0(0.0-0.0)$ & $0.00(0.00-0.01)$ & $0.9(0.8-1.0)$ & $2.6(2.4-2.9)$ & $7.1(5.8-8.4)$ & $<.0001$ \\
\hline Platelets (U) & $3.0(2.8-3.2)$ & $0(0)$ & $0(0)$ & $2.9(2.7-3.2)$ & $6.1(5.6-6.6)$ & $17.6(14.1-21.2)$ & $<.0001$ \\
\hline PCC & $33(1.2)$ & $0(0)$ & $0(0)$ & $11(1.1)$ & $12(2.1)$ & $10(10.5)$ & $<.0001$ \\
\hline rFVIIa & $2(0.1)$ & $0(0)$ & $0(0)$ & $0(0)$ & $0(0)$ & $2(2.1)$ & $<.0001$ \\
\hline
\end{tabular}

Data presented as mean (95\% confidence intervals) for continuous variables and absolute number (\%) for nominal variables. UDPB, Universal definition of perioperative bleeding; $I C U$, intensive care unit; $I A B P$, intra-aortic balloon pump; $R R T$, renal replacement therapy; $A F$, atrial fibrillation; $R B C$, red blood cell; $P C C$, prothrombin complex concentrate; $r F V I I a$, recombinant coagulation factor VIIa.

\begin{abstract}
Spearman test. Predictors of an increasing class of UDPB were identified by ordinal regression using a complementary log-log link. Because UDPB classes 3 and 4 were associated with a significantly greater risk of mortality and other adverse events, UDPB was dichotomized (UDPB class $0-2$ vs 3-4). Logistic regression analysis was performed in a backward fashion. The model was calibrated using the Hosmer-Lemeshow goodness-of-fit test. Model discrimination was evaluated using the area under the receiver operating characteristic curve. Linear regression was used to evaluate the effect of the UDPB class adjusted for other covariates on the length of stay in the ICU. Only variables with $P<.05$ on univariable analysis were included in the regression models to avoid overfitting. The Kaplan-Meier method was used to estimate late survival. Cox proportional hazards analysis was performed to adjust the UDPB class for variables significantly associated with poor late survival. Probabilities (propensity scores) estimated by ordinal and logistic regression analyses were used to adjust the risk of adverse events associated with either nominal (multilevel propensity score-adjusted analysis) or dichotomized UDPB (binary propensity score-adjusted analysis) classes. Propensity scores were calculated by nonparsimonious regression models, entering all baseline and operative variables listed in Tables E2 and E3. The Papworth bleeding risk score was not included in these regression models. All tests were 2-sided with the $\alpha$ level set at 0.05 for statistical significance.
\end{abstract}

\section{RESULTS \\ Effect of UDPB Class on Immediate and Late Postoperative Outcomes}

Table 1 and Figure 1 summarize the outcome of patients according to the different UDPB classes. An increasing UDPB class was associated with an increased risk of in-hospital mortality $(P=.002)$, stroke $(P=.023)$, low cardiac output $(P<.0001)$, prolonged use of inotropes $(P<.0001)$, renal replacement therapy $(P<.0001)$, length of stay in the ICU $(P<.0001)$, and late mortality $(P<.0001)$, as assessed by multilevel propensity score-adjusted analysis (probabilities for each of the 5 classes were obtained from ordinal regression). The increased risk of late mortality associated with a higher UDPB class was confirmed in regular multivariate analysis adjusted for age, estimated glomerular filtration rate, diabetes, extracardiac arteriopathy, and left ventricular ejection fraction $(P<.0001$, class 1: hazard ratio [HR], $0.894 ; 95 \%$ confidence interval [CI], 0.485-1.650; class 2 : HR, 1.665; 95\% CI, 1.142-2.427; class 3: HR, 2.092; 95\% CI, 1.411-3.101; class 4: HR, 4.651; 95\% CI, 2.819-7.675; Figure 2).

The propensity score-adjusted analysis (probabilities obtained from logistic regression) showed that UDPB

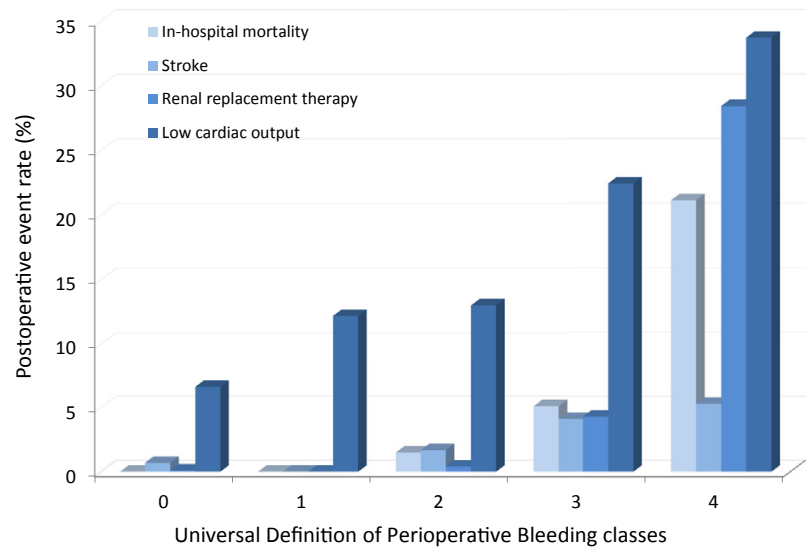

FIGURE 1. Postoperative rates of in-hospital mortality $(P<.0001)$, stroke $(P<.0001)$, renal replacement therapy $(P<.0001)$, and low cardiac output (cardiac index $<2.0 \mathrm{~L} / \mathrm{min} / \mathrm{m}^{2}$ for $\geq 2$ different measurements, $P<.0001$ ) stratified by universal definition of perioperative bleeding class. 


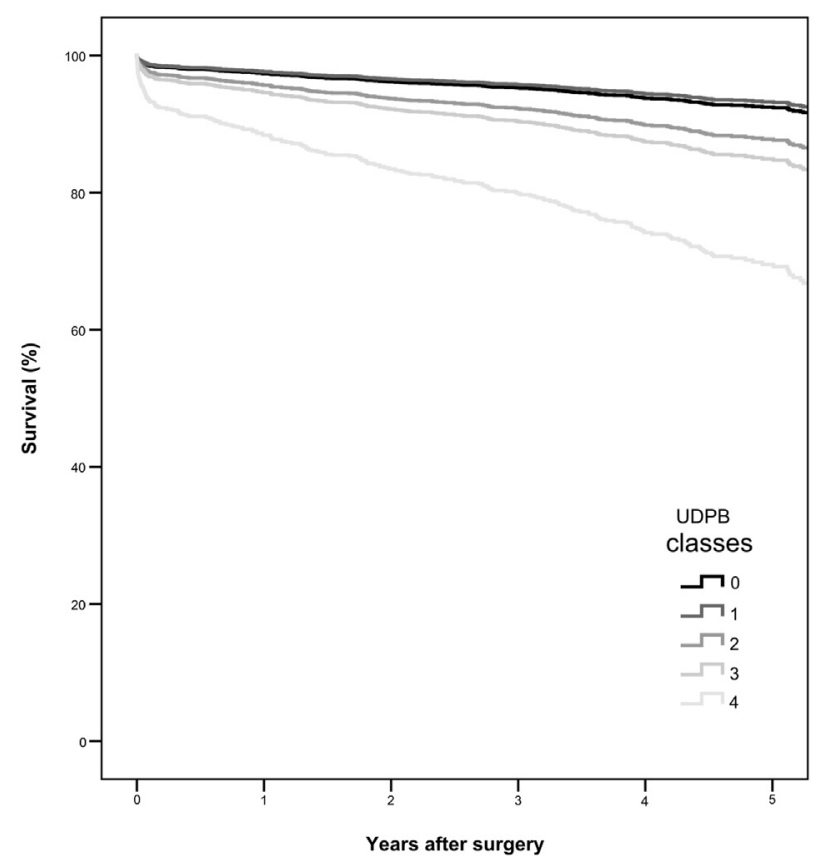

FIGURE 2. Cox proportional hazards estimate of late survival after coronary artery bypass surgery stratified by universal definition of perioperative bleeding $(U D P B)$ class (adjusted analysis for age, estimated glomerular filtration rate, diabetes, extracardiac arteriopathy, and left ventricular ejection fraction: $P<.0001$, class 1 : hazard ratio [HR], 0.894; $95 \%$ confidence interval $[\mathrm{CI}], 0.485-1.650$; class 2 : HR, 1.665; 95\% CI, 1.142-2.427; class 3: HR, 2.092; 95\% CI, 1.411-3.101; class 4: HR, 4.651; 95\% CI, 2.819-7.675).

classes 3 and 4 were significantly associated with an increased risk of in-hospital mortality (odds ratio [OR], 4.081; 95\% CI, 2.115-7.873; $P<.0001$ ), stroke (OR, $3.095 ; 95 \%$ CI, $1.665-5.751 ; P<.0001)$, low cardiac output syndrome (OR, 1.936; 95\% CI, 1.508-2.485; $P<.0001$ ), prolonged use of inotropes (OR, 2.408; 95\% CI, $1.970-2.945 ; P<.0001)$, renal replacement therapy (OR, 19.754; 95\% CI, 7.580-51.481; $P<.0001)$, and length of ICU stay (B, 1.549; 95\% CI, 1.325-1.756; $P<.0001$ ). Similarly, binary propensity score-adjusted Cox analysis showed that UDPB classes 3 and 4 were associated with significantly poorer survival (HR, $1.665 ; 95 \% \mathrm{CI}$, 1.277-2.171; $P<.0001)$.

\section{Predictors of Perioperative Bleeding Severity}

Tables E2 and E3 summarize the baseline and operative variables according to the different UDPB classes. The Papworth risk score was significantly associated with UDPB class (Spearman's test, $P<.0001$; rho, 0.349; rate of UDPB class 3 and 4 stratified by Papworth risk score: $0,12.1 \% ; 1,23.9 \% ; 2,37.5 \%$; and $3,45.0 \% ; P<.0001$; Table E2).

Ordinal regression analysis showed that a number of variables were associated with an increasing UDPB class
TABLE 2. Results of ordinal regression for identification of predictors of bleeding severity using the universal definition of perioperative bleeding

\begin{tabular}{lcc}
\hline \multicolumn{1}{c}{ Variable } & $\boldsymbol{P}$ value & $\begin{array}{c}\text { Estimate (lower and } \\
\text { upper bound) }\end{array}$ \\
\hline Age & $<.0001$ & $0.013(0.008,0.018)$ \\
Male gender & .012 & $-0.140(-0.249,-0.030)$ \\
BMI & $<.0001$ & $-0.026(-0.035,-0.016)$ \\
Baseline eGFR & $<.0001$ & $-0.004(-0.005,-0.002)$ \\
Baseline hemoglobin & $<.0001$ & $-0.009(-0.012,-0.006)$ \\
No dialysis & $<.0001$ & $-0.856(-1.412,-0.300)$ \\
Operation type & & \\
$\quad$ Elective & $<.0001$ & $-0.774(-0.984,-0.564)$ \\
$\quad$ Urgent & $<.0001$ & $-0.515(-0.709,-0.322)$ \\
$\quad$ Emergency & & \\
On-pump surgery & $<.0001$ & $0.354(0.270,0.437)$ \\
Potent antiplatelet* agent & $<.0001$ & $-0.245(-0.365,-0.125)$ \\
$\quad$ pause $\geq 5 \mathrm{~d}$ & & \\
Warfarin pause $\geq 2 \mathrm{~d}$ & $<.0001$ & $-0.582(-0.845,-0.319)$ \\
No critical preoperative status & $<.0001$ & $-0.357(-0.534,-0.180)$ \\
\hline BMT, Body
\end{tabular}

BMI, Body mass index; eGFR, estimated glomerular filtration rate. *Clopidogrel, ticagrelor, and prasugrel.

(Table 2; Pearson's chi-square test, $P<.0001$; missing cases, 22).

Because UDPB classes 3 and 4 were associated with a markedly greater risk of mortality and other adverse events (Table 1, Figures 1 and 2), we chose this dichotomized variable for additional analysis. The bleeding that led to a UDPB designation of class 3 or 4 was observed in $33.3 \%$ of the patients who had undergone urgent or emergency surgery and in $59.9 \%$ of the patients who had undergone emergency surgery.

Logistic regression (Hosmer-Lemeshow test, $P=.756$; missing cases, 22) showed a number of variables were predictive of UDPB classes 3 and 4 (Table 3 ) and confirmed the results of the ordinal regression analysis. The obtained probabilities had an area under the receiver operating characteristic curve of 0.726 (95\% CI, 0.703-0.749). Similar findings were observed when continuous variables were substituted by their dichotomized counterparts (age, $>75$ years: OR, $1.403 ; 95 \%$ CI, $1.125-1.749$; body mass in$\operatorname{dex}[\mathrm{BMI}],<25 \mathrm{~kg} / \mathrm{m}^{2}$ : OR, 1.624, 95\% CI, 1.321-1.996; estimated glomerular filtration rate $<60 \mathrm{~mL} / \mathrm{min} / 1.73 \mathrm{~m}^{2}$ : OR, 1.506; 95\% CI, 1.155-1.962).

\section{DISCUSSION}

The present analysis showed that the UDPB classification effectively stratifies the severity of bleeding and the related increased need of blood products, demonstrated by the significantly increased risk of adverse events among the highest UDPB classes. The validity of this classification was further confirmed by the identification of a number of baseline and operative variables known to be associated with an increased risk of excessive bleeding. Therefore, 
TABLE 3. Results of logistic regression for identification of predictors of severe and massive bleeding (class 3-4 of UDPB)

\begin{tabular}{lcc}
\hline \multicolumn{1}{c}{ Variable } & $\boldsymbol{P}$ value & OR $(\mathbf{9 5} \% \mathbf{C I})$ \\
\hline Age & .003 & $1.017(1.006-1.029)$ \\
Female sex & .001 & $1.546(1.237-1.932)$ \\
BMI & $<.0001$ & $0.951(0.929-0.972)$ \\
Baseline eGFR & .001 & $0.993(0.989-0.996)$ \\
Baseline hemoglobin & $<.0001$ & $0.982(0.976-0.989)$ \\
Operation type & $<.0001$ & \\
$\quad$ Elective & & - \\
$\quad$ Urgent & & $1.511(1.208-1.890)$ \\
$\quad$ Emergency & & $3.962(2.626-5.980)$ \\
On-pump surgery & $<.0001$ & $1.779(1.471-2.153)$ \\
Potent antiplatelet* pause $<5 \mathrm{~d}$ & .006 & $1.415(1.104-1.814)$ \\
Warfarin pause $<2 \mathrm{~d}$ & $<.0001$ & $3.499(2.110-5.803)$ \\
Critical preoperative status & $<.0001$ & $1.756(1.246-2.475)$ \\
\hline OR, Odd
\end{tabular}

$O R$, Odds ratio; $C I$, confidence interval; $B M I$, body mass index; $e G F R$, estimated glomerular filtration rate. ${ }^{*}$ Clopidogrel, ticagrelor, and prasugrel.

the UDPB classification is a promising research tool for appropriate stratification of the perioperative risk of bleeding. This will allow objective evaluation of the measures adopted to reduce blood loss and the need for blood transfusion. Furthermore, this classification could be useful for estimating the prognostic effect of excessive bleeding.

\section{Factors Predicting Increased UDPB Classes}

The easy-to-use Papworth bleeding risk score correlated significantly with increasing UDPB classes on univariable analysis. Although the Papworth bleeding risk score itself was not statistically significant on multivariable analysis, age $>75$ years, BMI $<25 \mathrm{~kg} / \mathrm{m}^{2}$, and urgent or emergency surgery, which determine the total risk score, were independent predictors of the severity of perioperative bleeding. In particular, a BMI of $<25 \mathrm{~kg} / \mathrm{m}^{2}$ seemed to work well in predicting an increased risk of perioperative bleeding and blood transfusion during coronary surgery. Our findings are in line with those from other studies demonstrating a BMI of $\geq 25 \mathrm{~kg} / \mathrm{m}^{2}$ was a significant independent predictor of a decreased need for intraoperative transfusion ${ }^{9,10}$ and decreased postoperative blood $\operatorname{loss}^{9}$ in CABG. The mechanisms through which a low BMI causes excessive bleeding are not known.

One of the significant factors associated with high UDPB classes was the baseline hemoglobin. Low preoperative hemoglobin is a remarkable risk factor for perioperative transfusion of RBCs. In previous studies, preoperative anemia was also reported to be an independent risk factor for adverse outcomes such as in-hospital mortality and stroke $^{11}$ and acute kidney injury ${ }^{11,12}$ after cardiac surgery. This is of clinical significance because of the potentially preventable nature of this risk factor by preoperative measures to increase the baseline hemoglobin level. ${ }^{13}$

Chronic kidney disease has been associated with perioperative bleeding in cardiac surgery. ${ }^{14,15}$ From the findings from previous studies, it is known that renal impairment can result in either thrombosis or bleeding owing to the changed interaction of the different components of the coagulation system, such as the coagulation cascade, platelets, and vessel wall. ${ }^{16}$ Factors termed "microparticles" have potent procoagulatory effects and probably induce coagulation in patients with renal insufficiency. However, they might also contain microRNA, thus inhibiting the function of platelets, resulting in a greater risk of bleeding. ${ }^{16}$

Potent antiplatelet agents were noted to be remarkably associated with perioperative bleeding and blood transfusion, which has already been demonstrated in previous studies. ${ }^{17}$ A preoperative pause of $<5$ days in the use of clopidogrel, prasugrel, or ticagrelor in our study was associated with a significant risk of severe or massive bleeding (UDPB class 3-4, OR, 1.415). Even greater was the risk of severe or massive bleeding when warfarin had not been discontinued for $\geq 2$ days before surgery (OR, 3.499). The use of other potent antithrombotic drugs, which were not evaluated in the present study, usually given to patients with acute coronary syndrome, might account for the independent effect of urgent or emergency surgery on perioperative bleeding.

As indicated by our findings, the use of cardiopulmonary bypass was an important predictor of excessive perioperative bleeding. CABG performed using cardiopulmonary bypass is known to be associated with greater rates of blood product transfusion and reoperation for perioperative bleeding compared with off-pump surgery. ${ }^{18,19}$

\section{Adverse Events}

A number of studies have shown that RBC transfusion can have a negative influence on the early and late outcomes of patients with acute coronary syndrome $\mathrm{e}^{20-22}$ and patients undergoing cardiac surgery. ${ }^{23-26}$ In the present study, the highest UDPB classes had an important effect on both short- and long-term survival after CABG. The decrease in survival seemed particularly evident during the first 2 to 3 postoperative months (Figure 2).

In our recent study, we found that RBC transfusion was associated with troponin release and an increased risk of type $\mathrm{V}$ myocardial infarction after elective off-pump coronary surgery. ${ }^{3}$ This might have resulted from the reduced deformability of stored RBCs, which might cause occlusion of the microcirculation. ${ }^{27,28}$ Additionally, the high free hemoglobin concentrations of stored blood might induce vasoconstriction of the microcirculation, ${ }^{29}$ and adenosine triphosphate-related vasodilatation might be prevented by the lower adenosine triphosphate levels of stored RBCs. ${ }^{30}$

In the present analysis, we observed a significantly increased incidence of stroke in patients in the highest UDPB classes (Figure 1, Table 1), confirming the findings of 2 previous studies. ${ }^{2,31}$ 
In addition to stroke, postoperative acute renal failure requiring renal replacement therapy, which was associated with high UDPB classes (in particular, in patients with UDPB class 4), can result from excessive bleeding and the need for massive RBC transfusions. Shimmer and colleagues $^{32}$ studied patients undergoing cardiac surgery and found that worsening of renal function after cardiac surgery is associated with the storage time and amount of the transfused RBC units.

Low cardiac output is a major adverse outcome associated with high UDPB classes after CABG. A study by Surgenor and colleagues ${ }^{33}$ showed that exposure to both hemodilutional anemia and RBC transfusion during on-pump CABG was associated with an increased risk of low cardiac output. The risk of low cardiac output was greater among patients exposed to intraoperative RBCs than among those with anemia alone. ${ }^{33}$

\section{Study Limitations}

The retrospective nature of our study was an important limitation. However, although some of the data might have been collected retrospectively, the data on the transfused blood products and blood loss were retrieved from prospective electronic registries, which can be considered reliable. The same applies to data regarding patient death. The present study assessed the prognostic effect of the UDPB classification in patients undergoing isolated CABG. Therefore, additional studies should be performed to evaluate its value for patients undergoing cardiac procedures other than $\mathrm{CABG}$.

\section{CONCLUSIONS}

High UDPB classes were associated with markedly poorer immediate and late outcomes. The risk of a poor outcome was particularly evident for UDPB classes 3 and 4. The UDPB classification is a promising research tool to assess the severity of bleeding and to estimate its prognostic effect after cardiac surgery. A number of risk factors, some potentially preventable, were associated with increased UDPB classes and should be the target of strategies aiming to decrease the risk of perioperative bleeding and the use of blood products.

\section{References}

1. Dyke C, Aronson S, Diatrich W, Hofmann A, Karkouti K, Levi M, et al. Universal definition of perioperative bleeding in adult cardiac surgery. J Thorac Cardiovasc Surg. 2014;147:1458-63.

2. Loor G, Rajeswaran J, Li L, Sabik JF III, Blackstone EH, McCrae KR, et al. The least of 3 evils: exposure to red blood cell transfusion, anemia, or both? J Thorac Cardiovasc Surg. 2013;146:1480-7.

3. Biancari F, Kinnunen EM. Red blood cell transfusion is associated with troponin release after elective off-pump coronary artery bypass surgery. Ann Thorac Surg. 2012;94:1901-7.

4. Levey AS, Bosch JP, Lewis JB, Greene T, Rogers N, Roth D. A more accurate method to estimate glomerular filtration rate from serum creatinine: a new prediction equation. Modification of Diet in Renal Disease Study Group. Ann Intern Med. 1999;130:461-70.

5. Nashef SA, Roques F, Sharples LD, Nilsson J, Smith C, Goldstone AR, et al. EuroSCORE II. Eur J Cardiothorac Surg. 2012;41:734-44.

6. Vuylsteke A, Pagel C, Gerrard C, Reddy B, Nashef S, Aldam P, et al. The Papworth bleeding risk score: a stratification scheme for identifying cardiac surgery patients at risk of excessive early postoperative bleeding. Eur J Cardiothorac Surg. 2011;39:924-31.

7. Biancari F, Mikkola R, Heikkinen J, Lahtinen J, Kettunen U, Juvonen T. Individual surgeon's impact on the risk of re-exploration for excessive bleeding after coronary artery bypass surgery. J Cardiothorac Vasc Anesth. 2012;26: 550-6.

8. Biancari F, Yli-Pyky S. Meta-analysis on the use of the Heartstring anastomotic device to prevent stroke in patients undergoing off-pump coronary artery bypass grafting. Eur J Cardiothorac Surg. 2011;40:1236-40.

9. Nolan HR, Davenport DL, Ramaiah C. BMI is an independent preoperative predictor of intraoperative transfusion and postoperative chest-tube output Int J Angiol. 2013;22:31-6.

10. Reeves BC, Ascione R, Chamberlain MH, Angelini GD. Effect of body mass index on early outcomes in patients undergoing coronary artery bypass surgery. J Am Coll Cardiol. 2003;42:668-76.

11. Karkouti K, Wijeysundera DN, Beattie WS. Risk associated with preoperative anemia in cardiac surgery: a multicenter cohort study. Circulation. 2008;117: 478-84.

12. De Santo L, Romano G, Della Corte A, de Simone V, Grimaldi F, Cotrufo M, et al. Preoperative anemia in patients undergoing coronary artery bypass grafting predicts acute kidney injury. J Thorac Cardiovasc Surg. 2009;138: 965-70.

13. Muñoz M, García-Erce JA, Cuenca J, Bisbe E, Naveira E. On the role of iron therapy for reducing allogeneic blood transfusion in orthopaedic surgery. Blood Transfus. 2012;10:8-22.

14. Acedillo RR, Shah M, Devereaux PJ, Li L, Iansavichus AV, Walsh M, et al The risk of perioperative bleeding in patients with chronic kidney disease: a systematic review and meta-analysis. Ann Surg. 2013;258:901-13.

15. Winkelmayer WC, Levin R, Avorn J. Chronic kidney disease as a risk factor for bleeding complications after coronary artery bypass surgery. Am J Kidney Dis. 2003;41:84-9.

16. Lutz J, Menke J, Sollinger D, Schinzel H, Thürmel K. Haemostasis in chronic kidney disease. Nephrol Dial Transplant. 2014;29:29-40.

17. Biancari F, Airaksinen KE, Lip GY. Benefits and risks of using clopidogrel before coronary artery bypass surgery: systematic review and meta-analysis of randomized trials and observational studies. J Thorac Cardiovasc Surg. 2012; 143:665-75

18. Lamy A, Devereaux PJ, Prabhakaran D, Taggart DP, Hu S, Paolasso E, et al. Off-pump or on-pump coronary-artery bypass grafting at 30 days. $N$ Engl $J$ Med. 2012;366:1489-97.

19. Duara R, Misra M, Bhuyan RR, Sarma PS, Jayakumar K. Does transfusion of residual cardiopulmonary bypass circuit blood increase postoperative bleeding? A prospective randomized study in patients undergoing on pump cardiopulmonary bypass. Asian J Transfus Sci. 2008;2:51-5.

20. Aronson D, Dann EJ, Bonstein L, Blich M, Kapeliovich M, Beyar R, et al Impact of red blood cell transfusion on clinical outcomes in patients with acute myocardial infarction. Am J Cardiol. 2008;102:115-9.

21. Cooper HA, Rao SV, Greenberg MD, Rumsey MP, McKenzie M, Alcorn KW et al. Conservative versus liberal red cell transfusion in acute myocardial infarction (the CRIT Randomized Pilot Study). Am J Cardiol. 2011;108:1108-11.

22. Singla I, Zahid M, Good CB, Macioce A, Sonel AF. Impact of blood transfusions in patients presenting with anemia and suspected acute coronary syndrome. Am J Cardiol. 2007;99:1119-21.

23. Hajjar LA, Vincent JL, Galas FR, Nakamura RE, Silva CM, Santos MH, et al Transfusion requirements after cardiac surgery: the TRACS randomized controlled trial. JAMA. 2010;304:1559-67.

24. Surgenor SD, Kramer RS, Olmstead EM, Ross CS, Sellke FW, Likosky DS, et al. The association of perioperative red blood cell transfusions and decreased long-term survival after cardiac surgery. Anesth Analg. 2009;108:1741-6.

25. Möhnle P, Snyder-Ramos SA, Miao Y, Kulier A, Böttiger BW, Levin J, et al Postoperative red blood cell transfusion and morbid outcome in uncomplicated cardiac surgery patients. Intensive Care Med. 2011;37:97-109.

26. LaPar DJ, Crosby IK, Ailawadi G, Ad N, Choi E, Spiess BD, et al. Blood product conservation is associated with improved outcomes and reduced costs after cardiac surgery. J Thorac Cardiovasc Surg. 2013;145:796-803. 
27. Wang D, Sun J, Solomon SB, Klein HG, Natanson C. Transfusion of older stored blood and risk of death: a meta-analysis. Transfusion. 2012;52:1184-95.

28. Koch CG, Li L, Sessler DI, Figueroa P, Hoeltge GA, Mihaljevic T, et al. Duration of red-cell storage and complications after cardiac surgery. N Engl J Med. 2008; 358:1229-39.

29. Donadee C, Raat NJ, Kanias T, Tejero J, Lee JS, Kelley EE, et al. Nitric oxide scavenging by red blood cell microparticles and cell-free hemoglobin as a mechanism for the red cell storage lesion. Circulation. 2011;124:465-76.

30. Hu H, Xenocostas A, Chin-Yee N, Lu X, Chin-Yee I, Feng Q. Transfusion of fresh but not old stored blood reduces infarct size and improves cardiac function after acute myocardial infarction in anemic rats. Crit Care Med. 2012;40:740-6.
31. Mikkola R, Gunn J, Heikkinen J, Wistbacka JO, Teittinen K, Kuttila K, et al. Use of blood products and risk of stroke after coronary artery bypass surgery. Blood Transfus. 2012;10:490-501.

32. Shimmer C, Hamouda K, Ozkur M, Sommer SP, Hain J, Aleksic I, et al. Influence of storage time and amount of red blood cell transfusion on postoperative renal function: an observational cohort study. Heart Lung Vessel. 2013;5:148-57.

33. Surgenor SD, DeFoe GR, Fillinger MP, Likosky DS, Groom RC, Clark C, et al. Intraoperative red blood cell transfusion during coronary artery bypass graft surgery increases the risk of postoperative low-output heart failure. Circulation. 2006;114:I43-8. 
TABLE E1. Bleeding severity stratified by universal definition of perioperative bleeding in adult cardiac surgery

\begin{tabular}{|c|c|c|c|c|c|c|c|c|c|}
\hline Bleeding severity & $\begin{array}{l}\text { Sternal } \\
\text { closure } \\
\text { delayed }\end{array}$ & $\begin{array}{c}\text { Blood loss } \\
\text { within } 12 \mathrm{~h}(\mathrm{~mL})\end{array}$ & $\operatorname{RBCs}(\mathrm{U})$ & $\operatorname{FFP}(\mathbf{U})$ & Platelets (U) & Cryoprecipitate & PCC & rFVIIa & $\begin{array}{c}\text { Re-exploration } \\
\text { or tamponade } \\
\end{array}$ \\
\hline Class 0 (insignificant) & No & $<600$ & 0 & 0 & 0 & No & No & No & No \\
\hline Class 1 (mild) & No & $601-800$ & 1 & 0 & 0 & No & No & No & No \\
\hline Class 2 (moderate) & No & $801-1000$ & $2-4$ & $2-4$ & Yes & Yes & Yes & No & No \\
\hline Class 3 (severe) & Yes & $1001-2000$ & $5-10$ & $5-10$ & NA & NA & NA & No & Yes \\
\hline Class 4 (massive) & NA & $>2000$ & $>10$ & $>10$ & NA & NA & NA & Yes & NA \\
\hline
\end{tabular}

Data from Dyke and colleagues. ${ }^{1} R B C$, Red blood cells; FFP, fresh frozen plasma; $P C C$, prothrombin complex concentrate; $r F V I I a$, recombinant activated factor VII; $N A$, not applicable.

TABLE E2. Baseline characteristics stratified by universal definition of perioperative bleeding

\begin{tabular}{|c|c|c|c|c|c|c|c|}
\hline \multirow[b]{2}{*}{ Characteristic } & \multirow{2}{*}{$\begin{array}{c}\text { Overall } \\
(n=2764)\end{array}$} & \multicolumn{5}{|c|}{ UDPB class } & \multirow[b]{2}{*}{$P$ value } \\
\hline & & $0(\mathbf{n}=756)$ & $1(n=286)$ & $2(n=1042)$ & $3(\mathbf{n}=\mathbf{5 8 5})$ & $4(n=95)$ & \\
\hline Age $(y)$ & $67.0(66.7-67.4)$ & $64.3(63.7-64.9)$ & $66.5(65.5-67.5)$ & $67.8(67.3-68.4)$ & $68.9(68.2-69.7)$ & $70.0(68.4-71.7)$ & $<.0001$ \\
\hline Female sex & $582(21.1)$ & $66(8.7)$ & 55 (19.2) & $276(26.5)$ & 168 (28.7) & 17 (17.9) & $<.0001$ \\
\hline Hemoglobin (mg/L) & $137(136-137)$ & 145 (144-146) & $139(137-140)$ & $134(133-135)$ & $131(129-132)$ & $127(123-131)$ & $<.0001$ \\
\hline BMI $\left(\mathrm{kg} / \mathrm{m}^{2}\right)$ & $28.1(27.9-28.2)$ & $29.3(29.0-29.6)$ & $27.9(27.4-28.4)$ & $27.7(27.5-28.0)$ & $27.2(26.8-27.5)$ & $27.7(26.6-28.8)$ & $<.0001$ \\
\hline $\mathrm{BMI}<25 \mathrm{~kg} / \mathrm{m}^{2}$ & $708(25.7)$ & $108(14.3)$ & 74 (25.9) & $290(27.9)$ & $206(35.5)$ & $30(33.3)$ & $<.0001$ \\
\hline Pulmonary disease & $274(9.9)$ & $64(8.5)$ & 34 (11.9) & $97(9.3)$ & 68 (11.6) & 11 (11.6) & .226 \\
\hline Diabetes mellitus & $788(28.5)$ & $212(28.0)$ & $78(27.3)$ & $286(27.4)$ & $186(31.8)$ & $26(27.4)$ & .402 \\
\hline Hypertension & $1547(56.0)$ & $417(55.2)$ & $159(55.6)$ & $591(56.7)$ & $329(56.2)$ & $51(53.7)$ & .955 \\
\hline Stroke & $95(3.4)$ & $28(3.7)$ & $8(2.8)$ & $29(2.8)$ & $25(4.3)$ & $5(5.3)$ & .400 \\
\hline Neurologic dysfunction & $50(1.8)$ & $9(1.2)$ & $8(2.8)$ & $18(1.7)$ & $14(2.4)$ & $1(1.1)$ & .323 \\
\hline Extracardiac arteriopathy & $265(9.6)$ & $57(7.5)$ & $24(8.4)$ & $96(9.2)$ & $69(11.8)$ & $19(20.0)$ & .001 \\
\hline $\mathrm{eGFR}\left(\mathrm{mL} / \mathrm{min} / 1.73 \mathrm{~m}^{2}\right)$ & $86.1(85.2-87.0)$ & $91.2(90.0-92.8)$ & $87.8(85.2-90.5)$ & $85.4(83.9-86.9)$ & $81.9(79.6-84.2)$ & $73.6(66.8-80.4)$ & $<.0001$ \\
\hline $\mathrm{eGFR}<60 \mathrm{~mL} / \mathrm{min} / 1.73 \mathrm{~m}^{2}$ & $350(12.7)$ & $43(5.7)$ & $30(10.5)$ & $143(13.8)$ & $107(18.4)$ & $27(28.7)$ & $<.0001$ \\
\hline Dialysis & $22(0.8)$ & $2(0.3)$ & $1(0.3)$ & $5(0.5)$ & $6(1.0)$ & $8(8.4)$ & $<.0001$ \\
\hline Recent MI & $1319(47.7)$ & $230(30.4)$ & $110(38.5)$ & $560(53.7)$ & $352(60.2)$ & $67(70.5)$ & $<.0001$ \\
\hline Previous PCI & $201(7.3)$ & $52(6.9)$ & $17(5.9)$ & $69(6.6)$ & $52(8.9)$ & 11 (11.6) & .168 \\
\hline Previous cardiac surgery & $46(1.7)$ & $8(1.1)$ & $2(0.7)$ & $18(1.7)$ & $11(1.9)$ & $7(7.4)$ & $<.0001$ \\
\hline Left main stenosis & $818(29.6)$ & $213(28.2)$ & $90(31.5)$ & $290(27.8)$ & $185(31.6)$ & $40(42.1)$ & .026 \\
\hline LVEF & & & & & & & $<.0001$ \\
\hline $30 \%-50 \%$ & $612(22.1)$ & $120(15.9)$ & $58(20.3)$ & $243(23.3)$ & $157(26.8)$ & $34(35.8)$ & \\
\hline$<30 \%$ & $87(3.1)$ & $9(1.2)$ & $3(1.0)$ & $35(3.4)$ & $34(5.8)$ & $6(6.3)$ & \\
\hline Critical preoperative status & $217(7.9)$ & $16(2.1)$ & $9(3.1)$ & $78(7.5)$ & $87(14.9)$ & $27(28.4)$ & $<.0001$ \\
\hline Delay from angiography (d) & $26.4(24.9-27.8)$ & $35.2(32.2-38.1)$ & $33.5(28.8-38.3)$ & $23.8(21.6-26.1)$ & $18.8(15.6-22.0)$ & $8.8(5.3-12.2)$ & $<.0001$ \\
\hline Papworth bleeding score & & & & & & & $<.0001$ \\
\hline 0 & $817(29.7)$ & $387(51.2)$ & $93(32.5)$ & $238(22.9)$ & $91(15.7)$ & $8(8.9)$ & \\
\hline 1 & $1207(43.8)$ & $297(39.3)$ & $137(47.9)$ & $485(46.6)$ & $251(43.2)$ & $37(41.1)$ & \\
\hline 2 & $589(21.4)$ & $65(8.6)$ & $48(16.8)$ & $255(24.5)$ & $184(31.7)$ & $37(41.1)$ & \\
\hline 3 & $140(5.1)$ & $7(0.9)$ & $8(2.8)$ & $62(6.0)$ & $55(9.5)$ & $8(8.9)$ & \\
\hline
\end{tabular}

Data presented as mean (95\% confidence intervals) for continuous variables and absolute number (\%). Definition criteria were according to EuroSCORE. UDPB, Universal definition of perioperative bleeding; $B M I$, body mass index; $e G F R$, estimated glomerular filtration rate; $M I$, myocardial infarction; $P C I$, percutaneous coronary intervention; $L V E F$, left ventricular ejection fraction. 
TABLE E3. Preoperative antithrombotic treatment and operative data stratified by universal definition of perioperative bleeding class

\begin{tabular}{|c|c|c|c|c|c|c|c|}
\hline \multirow[b]{2}{*}{ Variable } & \multirow[b]{2}{*}{ Overall $(n=2764)$} & \multicolumn{5}{|c|}{ UDPB class } & \multirow[b]{2}{*}{$P$ valuc } \\
\hline & & $0(n=756)$ & $1(n=286)$ & $2(n=1042)$ & $3(\mathbf{n}=\mathbf{5 8 5})$ & $4(n=95)$ & \\
\hline \multicolumn{8}{|l|}{ Preoperative antithrombotic agents } \\
\hline Warfarin & $233(8.4)$ & $35(4.6)$ & $13(4.5)$ & $92(8.8)$ & $83(14.2)$ & $10(10.5)$ & $<.0001$ \\
\hline Warfarin pause $<2 \mathrm{~d}$ & $77(2.8)$ & $2(0.3)$ & $2(0.7)$ & $30(2.9)$ & $38(6.5)$ & $5(5.3)$ & $<.0001$ \\
\hline Clopidogrel & $831(30.1)$ & $134(17.7)$ & $58(20.3)$ & $364(34.9)$ & $235(40.2)$ & $40(42.1)$ & $<.0001$ \\
\hline Clopidogrel pause $<5 \mathrm{~d}$ & $480(17.4)$ & $57(7.5)$ & $27(9.4)$ & 215 (20.6) & $152(26.0)$ & $29(30.5)$ & $<.0001$ \\
\hline Ticagrelor & $73(2.6)$ & $20(2.6)$ & $8(2.8)$ & $22(2.1)$ & $15(2.6)$ & $8(8.4)$ & .009 \\
\hline Ticagrelor pause $<5 \mathrm{~d}$ & $37(1.3)$ & $9(1.2)$ & $3(1.0)$ & $9(0.9)$ & $9(1.5)$ & $7(7.4)$ & $<.0001$ \\
\hline Prasugrel & $2(0.1)$ & $0(0)$ & $0(0)$ & $1(0.1)$ & $1(0.2)$ & $0(0)$ & .793 \\
\hline Prasugrel pause $<5 \mathrm{~d}$ & $1(0.0)$ & $0(0)$ & $0(0)$ & $0(0)$ & $1(0.2)$ & $0(0)$ & .444 \\
\hline Potent antiplatelet* pause $<5 \mathrm{~d}$ & $512(18.5)$ & $65(8.6)$ & $29(10.1)$ & $223(21.4)$ & $161(27.5)$ & $34(35.8)$ & $<.0001$ \\
\hline \multicolumn{8}{|l|}{ Operative data } \\
\hline Operation type & & & & & & & $<.0001$ \\
\hline Elective & 1260 (45.6) & $498(65.9)$ & $155(54.2)$ & $413(39.6)$ & $177(30.3)$ & $17(18.1)$ & \\
\hline Urgent & $1306(47.3)$ & $251(33.2)$ & $127(44.4)$ & $561(53.8)$ & $323(55.2)$ & $44(46.8)$ & \\
\hline Emergency & $197(7.1)$ & $7(0.9)$ & $4(1.4)$ & $68(6.5)$ & $85(14.5)$ & $33(35.1)$ & \\
\hline Off-pump coronary surgery & $1510(54.6)$ & $490(64.8)$ & $161(56.3)$ & $537(51.5)$ & $288(49.2)$ & $34(35.8)$ & $<.0001$ \\
\hline Distal anastomoses (n) & $4.0(3.9-4.0)$ & $4.0(3.9-4.0)$ & $4.0(3.9-4.1)$ & $3.9(3.9-4.0)$ & $4.0(3.9-4.1)$ & $3.8(3.6-4.0)$ & .104 \\
\hline Individual surgeon & - & - & - & - & - & - & .010 \\
\hline Intraoperative bleeding $(\mathrm{mL})$ & $418(404-433)$ & $359(340-379)$ & $376(346-406)$ & $399(380-418)$ & $516(470-562)$ & $659(501-818)$ & $<.0001$ \\
\hline
\end{tabular}

Data presented as mean ( $95 \%$ confidence intervals) for continuous variables and absolute number (\%) for nominal variables. UDPB, Universal definition of perioperative bleeding. *Clopidogrel, ticagrelor, and prasugrel. 